\title{
Epidemiology, Susceptibility, and Risk Factors Associated with Mortality in Carbapenem-Resistant Gram-Negative Bacterial Infections Among Abdominal Solid Organ Transplant Recipients: A Retrospective Cohort Study
}

\author{
Di Wu $\cdot$ Chunmei Chen · Taohua Liu • Yan Jia • Qiquan Wan • \\ Jie Peng
}

Received: January 1, 2021 / Accepted: January 29, 2021 / Published online: February 21, 2021

(C) The Author(s) 2021

\section{ABSTRACT}

Introduction: Carbapenem-resistant gram-negative bacteria (CR-GNB) can cause life-threatening infections among abdominal solid organ transplantation (ASOT) recipients. This study aimed to investigate the epidemiology and drug susceptibility of CR-GNB pathogens and identity the risk factors associated with 90-day crude mortality of CR-GNB infections among ASOT recipients.

Methods: We retrospectively reviewed the clinical characteristics, drug resistance rate, and risk factors associated with mortality in CR-GNB infections among ASOT recipients between August 1, 2013, and August 1, 2020. The Cox

Supplementary Information The online version contains supplementary material available at https:// doi.org/10.1007/s40121-021-00411-z.

D. Wu $\cdot$ Y. Jia $\cdot$ J. Peng $(\varangle)$

Department of Gastroenterology, Xiangya Hospital, Central South University, Changsha, Hunan, China e-mail: pengjie2014@csu.edu.cn

C. Chen

Department of Pediatrics, the Seventh Affiliated

Hospital, Sun Yat-Sen University, Shenzhen,

Guangdong, China

T. Liu . Q. Wan $(\bowtie)$

Transplantation Center, the Third Xiangya Hospital, Central South University, Changsha, Hunan, China e-mail: 13548685542@163.com regression model was performed to identify the independent risk factors for mortality.

Results: During the 8-year period, CR-GNB infections occurred in 153 of 1452 (10.5\%) recipients, and 23 of 153 (15.0\%) patients died. The most common pathogen was Acinetobacter baumannii $(n=47)$. The drug resistance rate of CR-GNB pathogens was relatively low to tigecycline $(33.3 \%)$ and high to other categories (> $60 \%$ ). There was a significant increasing trend in drug resistance to tigecycline as time went on (from 24 to $40 \%, P=0.04$ ). The independent risk factors for mortality were mechanical ventilation (hazard ratio $7.40,95 \%$ confidence interval 2.69-20.38, $P<0.001$ ), septic shock (hazard ratio $7.41,95 \%$ confidence interval 2.86-19.23, $P<0.001)$, and platelet count $<$ $50,000 / \mathrm{mm}^{3}$ (hazard ratio $4.00,95 \%$ confidence interval 1.49-10.76, $P=0.006$ ).

Conclusion: CR-GNB is widespread with high prevalence and mortality rates among ASOT recipients. Mechanical ventilation, septic shock, and low platelet count represent three independent risk factors related to the mortality of ASOT recipients with CR-GNB infection. We suggest that tigecycline may be used under rigorous management because of the significant increasing risk of drug resistance.

Keywords: Abdominal solid organ transplant; Carbapenem-resistant; Drug resistance rate; Mortality; Risk factor 


\section{Key Summary Points}

\section{Why carry out this study?}

Carbapenem resistant gram-negative bacteria (CR-GNB) can cause lifethreatening infections among abdominal solid organ transplantation (ASOT) recipients.

This study aimed to shed light on the improvement of clinical outcomes and antimicrobial regimens for CR-GNB infections among this special patient population.

\section{What was learned from the study?}

CR-GNB is widespread with high prevalence and mortality rates among ASOT recipients in China.

Mechanical ventilation, septic shock, and low platelet count represent three independent risk factors related to the mortality of ASOT recipients with CRGNB infections.

There was a significant increase in the drug resistance of CR-GNB to tigecycline as time went on, and we suggest that tigecycline may be used for ASOT recipients under rigorous management.

\section{DIGITAL FEATURES}

This article is published with digital features, including a summary slide, to facilitate understanding of the article. To view digital features for this article go to https://doi.org/10.6084/ m9.figshare.13655804.

\section{INTRODUCTION}

Carbapenem-resistant gram-negative bacteria (CR-GNB), including carbapenem-resistant Klebsiella pneumoniae (CRKP), -Acinetobacter baumannii (CRAB), and -Pseudomonas aeruginosa (CRPA), and so on, have emerged as a glaring global public health crisis with very few effective treatment regimens and are associated with a high mortality $[1,2]$. Abdominal solid organ transplantation (ASOT) has already been identified as a risk factor for CR-GNB infections. To date, several previous studies have investigated the worldwide spread of carbapenem-resistant Enterobacteriaceae (CRE) infections among ASOT recipients, showing mortality rates up to $71 \%$ [3]. It is a great challenge to make antimicrobial decisions in these patients because CR-GNBs are mostly extensively drug resistant (XDR) and only susceptible to a few antibiotics. CRKP bloodstream infections led to a mortality rate as high as $82 \%$ after liver transplantation [4], and the mortality associated with CRAB infections among kidney recipients was also up to 56\% [5].

Comparative drug studies focused on CRGNB infections in ASOT recipients are limited, and most failed to differentiate between transplant and nontransplant patients. Although some studies have been carried out on CRE or $\mathrm{CRAB}$ infections, few have investigated the epidemiology, drug resistance, and clinical outcomes of ASOT recipients with CR-GNB infections in China [6, 7].

This study therefore set out to characterize the epidemiology, microbiology, and risk factors related to 90-day mortality among ASOT recipients with CR-GNB infections. Thus, our findings may shed light on the improvement of clinical outcomes and the antimicrobial regimen for CR-GNB infections among this special patient population.

\section{METHODS}

\section{Design}

All the electrical medical records of 1452 ASOT recipients from August 1, 2013, to August 1, 2020, were retrospectively reviewed. As Fig. S1 shows, a two-part analysis was performed (1) to evaluate the risk factors associated with 90-day mortality and (2) to identify the drug resistance of CR-GNB pathogens. 


\section{Setting}

The retrospective cohort study was performed at the Third Xiangya Hospital of Central South University, an 1800-bed tertiary-care teaching hospital with a long-term ASOT program (annual average of 180 kidney and 35 liver transplantations), Changsha, China.

\section{Patients}

Patients $<16$ or $>80$ years old were excluded. There were only two sources of organs harvested for transplantation: living-related donors and donors after citizen's death. The prophylactic regimen used $1 \mathrm{~h}$ before transplantation was beta-lactamase inhibitors/semisynthetic penicillin, second- or third-generation cephalosporins, or carbapenems. According to the result of the culture before transplantation, a precise antibiotic was given within $72 \mathrm{~h}$ after transplantation. The treatment we recorded was the initial regimen after obtaining the microbiology profile. Tigecycline was used at $50 \mathrm{mg}$ every $12 \mathrm{~h}$ (100 mg the first time) and mostly in the abdominal cavity or deep wounds and skin infections instead of bloodstream infections as monotherapy. High-dose (2 $\mathrm{g}$ every $8 \mathrm{~h}$ ), extended-infusion meropenem (over $3 \mathrm{~h}$ ) was considered an appropriate therapy for initial treatment. Due to limited drug resistance tests of polymyxin and ceftazidime-avibactam, prescriptions of both antibiotics as effective options depended on the patient's condition. Data on the subsequent microbiology profile and corresponding treatment were not collected. For patients experiencing more than one episode of CR-GNB infection, only the first episode was included.

\section{Definition and Microbiology}

The onset of CR-GNB infections referred to the collection date of the first positive culture with clinical evidence of infections. Patients with positive microbiology results, according to the criteria of the Centers for Disease Control, were defined as having infections [8]. Donor-derived infections were defined as the same infections that were transmitted from the donor to more than one recipient [9].

Appropriate empirical antimicrobial therapy indicated that antibiotics susceptible to CRGNB in vitro were prescribed to treat suspected CR-GNB infections within $48 \mathrm{~h}$ after having drawn the cultures of specimens. Treatment during the initial stage of infections was categorized as monotherapy or combination therapy. Combination therapy was defined as treatment with two or more agents active in vitro against the infecting strain. Septic shock was diagnosed in recipients with CR-GNB infections who required vasopressor therapy to maintain mean arterial pressure of at least $65 \mathrm{mmHg}$ with serum lactate level $>2 \mathrm{mmol} / \mathrm{l}$ after adequate fluid resuscitation [10]. Crude mortality included all causes of death within 90 days after the onset of infections.

Identification and antimicrobial susceptibility testing of CR-GNB were carried out using the Vitek-2 system (bioMérieux, Marcy L'etoile, France). Antimicrobial susceptibility was determined by the Kerby-Bauer disk diffusion method, and the minimum inhibitory concentration was measured by agar dilution in the National Committee for Clinical Laboratory Standards guidelines. All the antimicrobial agents were products of Oxoid Ltd., Hampshire, UK. Intermediate susceptibility to the antibiotics was considered as resistance. The strain was considered to be CR-GNB when the minimal inhibitory concentration of meropenem or imipenem was $\geq 2 \mathrm{mg} / \mathrm{l}$ [11].

\section{Data Collection and Variables}

The clinical and demographic characteristics included: age, sex, hallmarks of infections (temperature and white blood cell count), site of infection, re-operation, mechanical ventilation, hospital-acquired infections, septic shock, empirical antimicrobial therapy, type of transplantation, and treatment regimen. Laboratory records, collected within the first $24 \mathrm{~h}$ after the culture was drawn, included: the serum albumin level, total bilirubin and creatinine levels, and platelet and lymphocyte counts. 


\section{Outcomes}

The follow-up period for all the patients was 3 months (90 days) after the onset of infections. The patients with $<3$ months of follow-up were excluded from the cohort. The clinical outcomes were divided into death and alive for risk analysis.

\section{Ethics}

The Institutional Review Board of the Third Xiangya Hospital of Central South University endorsed this study protocol prior to data collection (number: 2020-S629). The Institutional Review Board approved the waiver of informed consent from patients because this was a retrospective cohort study where information was obtained from electrical medical records and this study did not directly interfere with the enrolled patients as the data were de-identified and anonymously analyzed. Our study was conducted according to the Declaration of Helsinki and the Declaration of Istanbul, and no donors influenced or paid for our study. As a privacy statement, the authors guarantee the confidentiality of the patient data.

\section{Statistical Analysis}

For continuous variables, data were expressed as median (25-75\% quartile) or mean $( \pm S D)$. Categorical variables were compared with the $\chi^{2}$ test or Fisher exact tests. Univariate analysis was applied to inspect the association between variables and mortality caused by CR-GNB infections. The follow-up time was analyzed and defined as days alive from the onset until day 90, and a Cox regression (forward likelihood ratio method) analysis was performed to model hazards using this time variable. Hazard ratio (HR) and 95\% confidence intervals (CI) were calculated to assess the strength of all relations. The Kaplan-Meier curve was used to describe the survival distribution, and the log rank test was used to compare survival time among all the independent risk factors. Statistical significance was defined as $P<0.05$ (twotailed), and all analyses were carried out using
SPSS 24.0 (IBM SPSS Statistics, IBM Corp., Armonk, NY, US).

\section{RESULTS}

\section{Clinical Characteristics of Patients with CR-GNB Infections}

During the 8-year cohort study period, CR-GNB infections occurred in 153 of 1452 (10.5\%) ASOT recipients including 1192 kidney and 260 liver recipients in the Third Xiangya hospital. The kidney and liver transplantation prevalence of CR-GNB infections was $8.7 \%$ and $18.8 \%$, respectively.

Table 1 shows the clinical characteristic, demographic, and laboratory data of patients with CR-GNB infections. The median age of 153 ASOT recipients was 43.3 years, with 141 grafts from donation after citizen's death and 12 grafts from living-related donors. Regarding the type of CR-GNB infections, urinary tract infection was the most common (31.4\%), followed by bacteremia (19.6\%) and pneumonia (19.6\%). Of these 153 patients, $82.4 \%$ (126 of 153) suffered from nosocomial origin infections and $65.4 \%$ (100 of 153) were infected by XDR pathogens. One hundred eight patients $(82.4 \%)$ did not receive appropriate empirical antibiotic treatments within $48 \mathrm{~h}$ after the onset of CR-GNB infections. Twenty-one (13.7\%) patients required mechanical ventilation support as a treatment for respiratory failure caused by the infections, and 18 (11.8\%) patients developed septic shock at the onset of infections. Twenty (13.1\%) patients acquired infections from the donor, and 57 (37.3\%) patients experienced multiple organism or site infections. The crude 90-day mortality rate was 23\% (15 of 153 ).

\section{Risk Factors for 90-Day Mortality of CR- GNB Infections in ASOT Recipients}

The comparison of death and alive groups is shown in Table 2. Nosocomial infections $(P=0.035)$, multiple infected organisms or sites $(P=0.003)$, intensive care unit stays $>7$ days $(P<0.001)$, mechanical ventilation $(P<0.001)$, 
Table 1 Clinical characteristic, demographic, and laboratory data of 153 carbapenem-resistant gram-negative bacterial infections among abdominal solid organ transplantation recipients

\begin{tabular}{|c|c|}
\hline Characteristics & Value \\
\hline Age, mean years $\pm S D$ & $43.3 \pm 12.3$ \\
\hline Sex, no. of males (\%) & $105(68.6)$ \\
\hline Median body temperature $\left({ }^{\circ} \mathrm{C}\right)$ at the onset (IQR) & $37.4(36.9-38.3)$ \\
\hline Nosocomial origin, $n(\%)$ & $126(82.4)$ \\
\hline Inappropriate empirical antimicrobial use, $n(\%)$ & $108(70.6)$ \\
\hline Mechanical ventilation, $n(\%)$ & $21(13.7)$ \\
\hline Septic shock, $n(\%)$ & $18(11.8)$ \\
\hline Re-operation, $n(\%)$ & $13(8.5)$ \\
\hline $\mathrm{RBC}$ transfusion during the perioperative period, units (IQR) & $2(0-15.63)$ \\
\hline Duration of surgery, hours (IQR) & $4(3-6)$ \\
\hline Duration of ICU stays, days (IQR) & $4(0-7)$ \\
\hline Hospitalization, days (IQR) & $28(17-44)$ \\
\hline Prophylaxis failure, no. of cases (\%) & $40(26.1)$ \\
\hline Multiple infected organisms or sites, $n(\%)$ & $57(37.3)$ \\
\hline \multicolumn{2}{|l|}{ Organ resource, no. of cases (\%) } \\
\hline $\mathrm{DCD}$ & $141(92.2)$ \\
\hline Living-related & $12(7.8)$ \\
\hline \multicolumn{2}{|l|}{ Type of infections, no. of cases (\%) } \\
\hline Urinary tract infection & $48(31.4)$ \\
\hline Bacteremia & $30(19.6)$ \\
\hline Pneumonia & $30(19.6)$ \\
\hline Deep wound and skin infection & $28(18.3)$ \\
\hline Abdominal cavity infection & $17(11.1)$ \\
\hline \multicolumn{2}{|l|}{ Patient immunosuppressant treatment, no. of cases (\%) } \\
\hline Cyclosporine A & $5(3.3)$ \\
\hline Tacrolimus & $145(94.8)$ \\
\hline No use of calcineurin inhibitor & $3(2)$ \\
\hline Donor-derived infections, no. of cases (\%) & $20(13.1)$ \\
\hline \multicolumn{2}{|l|}{ Type of transplantation, no. of cases (\%) } \\
\hline Kidney & $104(68)$ \\
\hline Liver & $49(32)$ \\
\hline
\end{tabular}


Table 1 continued

\begin{tabular}{|c|c|}
\hline Characteristics & Value \\
\hline Lymphocyte count $<300 / \mathrm{mm}^{3}$ & $52(34)$ \\
\hline Albumin $<30 \mathrm{~g} / \mathrm{l}$ & $12(7.8)$ \\
\hline WBC count $>15,000 / \mathrm{mm}^{3}$ & $24(15.7)$ \\
\hline Platelet count $<50,000 / \mathrm{mm}^{3}$ & $24(15.7)$ \\
\hline Creatinine $>1.8 \mathrm{mg} / \mathrm{dl}$ & $70(45.8)$ \\
\hline Total bilirubin $>2.5 \mathrm{mg} / \mathrm{dl}$ & $31(20.3)$ \\
\hline \multicolumn{2}{|l|}{ Time of infection onset, no. of cases (\%) } \\
\hline$<1$ week posttransplant & $65(42.5)$ \\
\hline 7-30 days posttransplant & $29(18.9)$ \\
\hline $31-60$ days posttransplant & $15(9.8)$ \\
\hline 61-90 days posttransplant & $14(9.2)$ \\
\hline$>90$ days posttransplant & $30(19.6)$ \\
\hline Treatment & $134(87.6)$ \\
\hline \multicolumn{2}{|l|}{ Monotherapy } \\
\hline Meropenem (high dose, extended infusion) & $38(24.8)$ \\
\hline Tigecycline & $25(16.3)$ \\
\hline Aminoglycosides & $19(12.4)$ \\
\hline Quinolone & $18(11.8)$ \\
\hline Sulfonamides & $12(7.8)$ \\
\hline Piperacillin-tazobactam & $12(7.8)$ \\
\hline Ceftazidime-avibactam & $10(6.5)$ \\
\hline Combination therapy & $19(12.4)$ \\
\hline Tigecycline and carbapenem & $9(5.9)$ \\
\hline Tigecycline and polymyxin & $3(2)$ \\
\hline Carbapenem and polymyxin & $3(2)$ \\
\hline Ceftazidime-avibactam and aztreonam & $3(2)$ \\
\hline Quinolone and carbapenem & $1(0.7)$ \\
\hline XDR bacterial infection, no. of cases (\%) & $100(65.4)$ \\
\hline Mortality, no. of cases (\%) & $23(15)$ \\
\hline
\end{tabular}

$S D$ standard deviation, $W B C$ white blood cells, $R B C$ red blood cells, $I Q R$ interquartile range, $D C D$ donors after citizen's death, $X D R$ extensively drug resistant, $I C U$ intensive care unit 
Table 2 Comparison of mortality and survival groups among carbapenem-resistant gram-negative bacterial infection recipients

\begin{tabular}{|c|c|c|c|}
\hline Characteristics & Mortality $(n=23)$ & Survival $(n=130)$ & $P$ \\
\hline Age $\geq 40$ years & $15(65.2)$ & $75(57.7)$ & 0.499 \\
\hline Male sex & $19(82.6)$ & $86(66.2)$ & 0.117 \\
\hline Temperature $\geq 39^{\circ} \mathrm{C}$ & $4(17.4)$ & $7(5.4)$ & 0.106 \\
\hline Inappropriate empirical antibiotic & $18(78.3)$ & $90(69.2)$ & 0.381 \\
\hline Nosocomial infection & $23(100)$ & $103(79.2)$ & $0.035^{*}$ \\
\hline Prophylaxis failure & $3(13)$ & $34(28.5)$ & 0.121 \\
\hline ICU stays $>7$ days & $19(82.6)$ & $15(11.5)$ & $<0.001^{*}$ \\
\hline Hospitalization $>30$ days & $10(43.5)$ & $56(43.1)$ & 0.971 \\
\hline $\mathrm{RBC}$ transfusion $>10$ units during perioperative period & $7(30.4)$ & $55(42.3)$ & 0.193 \\
\hline Duration of surgery $>8 \mathrm{~h}$ & $5(21.7)$ & $34(26.2)$ & 0.873 \\
\hline Liver transplantation & $10(43.5)$ & $39(30)$ & 0.202 \\
\hline Bacteremia & $4(17.4)$ & $26(20)$ & 0.996 \\
\hline Urinary tract infection & $4(17.4)$ & $44(33.8)$ & 0.117 \\
\hline Pneumonia & $9(39.1)$ & $21(16.2)$ & $0.023^{*}$ \\
\hline Deep wound and skin infection & $3(13)$ & $25(19.2)$ & 0.678 \\
\hline Abdominal cavity infection & $3(13)$ & $14(10.8)$ & 0.968 \\
\hline Early-onset infection & $14(60.9)$ & $102(78.5)$ & 0.069 \\
\hline Re-operation & $2(8.7)$ & $11(8.5)$ & 0.970 \\
\hline Carbapenem-resistant Enterobacteriaceae & $9(39.1)$ & $66(50.8)$ & 0.303 \\
\hline Carbapenem-resistant Acinetobacter baumannii & $11(47.8)$ & $36(27.7)$ & 0.054 \\
\hline Multiple infected organisms or sites & $15(65.2)$ & $42(32.3)$ & $0.003^{*}$ \\
\hline Mechanical ventilation & $15(65.2)$ & $6(4.6)$ & $<0.001^{*}$ \\
\hline Donor-derived infection & $3(13)$ & $17(13.1)$ & 0.997 \\
\hline Use of tacrolimus & $20(87)$ & $125(96.2)$ & 0.187 \\
\hline Septic shock & $11(47.8)$ & $7(5.4)$ & $<0.001^{*}$ \\
\hline Platelet count $<50,000 / \mathrm{mm}^{3}$ & $12(52.2)$ & $12(9.2)$ & $<0.001^{*}$ \\
\hline Lymphocyte count $<300 / \mathrm{mm}^{3}$ & $10(43.5)$ & $42(32.3)$ & 0.297 \\
\hline Albumin $<30 \mathrm{~g} / 1$ & $5(21.7)$ & $7(10.2)$ & $0.023^{*}$ \\
\hline WBC count $>15,000 / \mathrm{mm}^{3}$ & $6(26.1)$ & $18(13.8)$ & 0.239 \\
\hline Creatinine $>1.8 \mathrm{mg} / \mathrm{dl}$ & $15(65.2)$ & $55(42.3)$ & $0.042^{*}$ \\
\hline
\end{tabular}


Table 2 continued

\begin{tabular}{lllc}
\hline Characteristics & Mortality $(\boldsymbol{n}=\mathbf{2 3})$ & Survival $(\boldsymbol{n}=\mathbf{1 3 0})$ & $\boldsymbol{P}$ \\
\hline Total bilirubin $>2.5 \mathrm{mg} / \mathrm{dl}$ & $11(47.8)$ & $20(15.4)$ & $0.001^{*}$ \\
Combination therapy & $11(47.8)$ & $8(6.2)$ & $<0.001^{*}$ \\
XDR bacterial infection & $20(87)$ & $80(61.5)$ & $0.018^{*}$ \\
\hline
\end{tabular}

$P$ value from Pearson's $\chi^{2}$ test or Fisher's exact test in univariate analysis. ${ }^{*} P$ values are statistically significant $W B C$ white blood cells, $R B C$ red blood cells, $X D R$ extensively drug resistant, $I C U$ intensive care unit

pneumonia $\quad(P=0.023)$ septic shock $(P<0.001)$, platelet count $<50,000 / \mathrm{mm}^{3}$ $(P<0.001)$, albumin $<30 \mathrm{~g} / \mathrm{l}(P=0.023)$, creatinine $>1.8 \mathrm{mg} / \mathrm{dl} \quad(P=0.042)$, total bilirubin $>2.5 \mathrm{mg} / \mathrm{dl} \quad(P=0.001), \quad$ combination therapy $(P<0.001)$, and XDR $(P=0.018)$ were significantly different between the two groups in the univariate analysis. In the multivariate analysis, mechanical ventilation (HR 7.40, 95\% CI 2.69-20.38, $P<0.001$ ), septic shock (HR 7.41, 95\% CI 2.86-19.23, $P<0.001)$, and platelet count $<50,000 / \mathrm{mm}^{3}$ (HR 4.00, 95\% CI 1.49-10.76, $P=0.006$ ) were three independent risk factors associated with crude mortality in Table 3. Figure 1 shows the survival time of patients with independent risk factors. For the outcome of patients with septic shock versus non-septic shock, the survival rate in the septic shock group was significantly lower (38.9\% vs. $90 \%, P<0.001)$. The survival rate was significantly lower in the patients requiring mechanical ventilation than in the patients without mechanical ventilation at the onset of infections $(28.6 \%$ vs. $93.9 \%, P<0.001)$. Compared with the platelet count $\geq 50,000 / \mathrm{mm}^{3}$ group, the survival rate was significantly lower in the platelet count $<50,000 / \mathrm{mm}^{3}$ group $(50 \%$ vs. 91.5\%, $P<0.001)$.

\section{Antimicrobial Susceptibility}

Figure 2 shows in detail the classification and percentage of the respective microorganisms. The most common pathogen of CR-GNB infections was CRAB $(n=47,31 \%)$, followed by
CRKP $\quad(n=39, \quad 25 \%), \quad$ carbapenem-resistant Escherichia. coli ( $n=20,13 \%)$, CR-Flavobacterium ( $n=16,10 \%)$, and others. Table 4 shows the antibiotic resistance rates of CR-GNB via a bacterial category. The drug resistance rates of CRAB and CRKP pathogens to all antibiotics tested were both $>50 \%$ except for tigecycline (TGC). The CR-GNB pathogens were relatively susceptible to TGC with a drug resistance rate as low as $33.3 \%$ and highly resistant to other categories (> 60\%). Figure 3 shows the comparison of resistance rates of CR-GNB to ten commonly used antibiotics during two halves of the period (2013-2016 vs. 2017-2020). A significantly increasing resistance trend of the TGC, from 24 to $40 \%$, was observed in our cohort as time went on $(P=0.04)$.

\section{DISCUSSION}

CR-GNBs have spread worldwide with limited choice of antibiotic therapy in recent years. ASOT recipients were vulnerable with all the definite risk factors related to CR-GNB infections, such as recurrent exposure to prophylactic antibiotics, intensive care unit, massive healthcare contact, and longer length of hospitalization. Rising mortality rates caused by CR-GNB infections have been reported in a variety of susceptible populations, including ASOT recipients $[3,12]$. This is the largest cohort study to characterize the epidemiology, risk factors, microbiologic spectrum, and clinical outcomes associated with CR-GNB infections among ASOT recipients in China to date. 
(A)

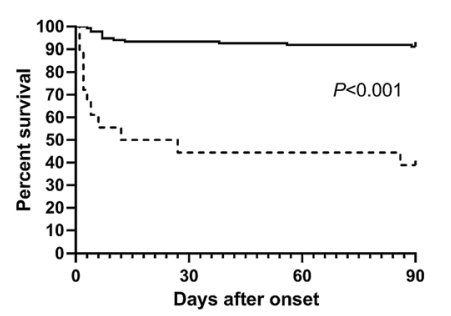

(C)

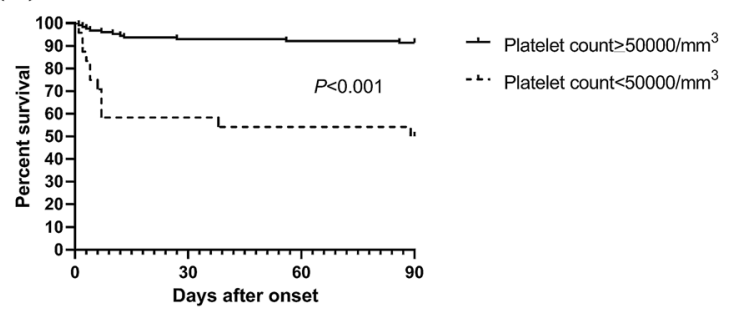

Fig. 1 Kaplan-Meier curve estimated survival rates between: a patients with septic shock vs. without septic shock $(38.9 \%$ vs. $90 \%, P<0.001)$; $(\mathbf{b})$ patients requiring mechanical ventilation vs. without mechanical ventilation
(B)

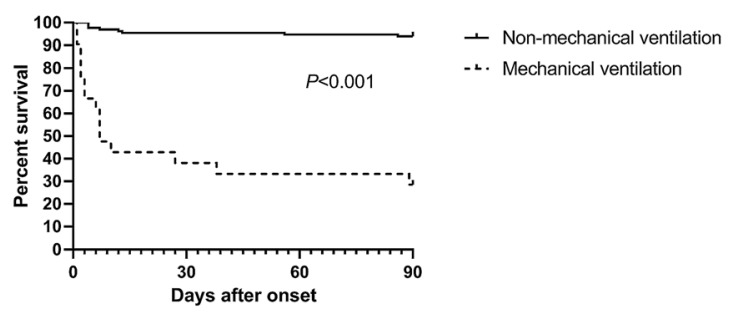

(28.6\% vs. 93.9\%, $P<0.001$ ); c platelet count $<50,000 /$ $\mathrm{mm}^{3}$ vs. platelet count $\geq 50,000 / \mathrm{mm}^{3}$ ( $50 \%$ vs. $91.5 \%$, $P<0.001)$

Table 3 Multivariate analysis of risk factors for mortality of carbapenem-resistant gram-negative bacterial infections after abdominal solid organ transplantation

\begin{tabular}{llc}
\hline Variable & HR $(\mathbf{9 5} \% \mathbf{C I})$ & $\boldsymbol{P}$ \\
\hline Mechanical ventilation & $7.40(2.69-20.38)$ & $<0.001$ \\
Septic shock & $7.41(2.86-19.23)$ & $<0.001$ \\
Platelet count $<50,000 / \mathrm{mm}^{3}$ & $4.00(1.49-10.76)$ & 0.006 \\
\hline
\end{tabular}

$H R$ hazard ratio, $C I$ confidence interval

In our present study, we revealed a morbidity and mortality rate of CR-GNB infections among ASOT recipients of up to $10.5 \%$ and $23 \%$, respectively. The prevalence of CR-GNB was higher in liver recipients $(18.8 \%)$ than in kidney recipients $(8.7 \%)$. The possible reasons may be the longer operation duration, more transfusions during surgery, and longer postoperative intensive care unit stay. To date and to our knowledge, this current analysis includes more deaths due to CR-GNB infections than previous studies, which only focused on one category of CR-GNB such as CRKP or CRAB $[4,13]$.

Mechanical ventilation, septic shock, and platelet count $<50,000 / \mathrm{mm}^{3}$ were found to be three independent risk factors associated with 90-day mortality. Septic shock was the most severe complication of infections in ASOT recipients with limited clinical approaches. The relationships among mortality, mechanical ventilation, and septic shock concluded from our present study were similar to those found in previous studies [7, 14-17]. This is not 


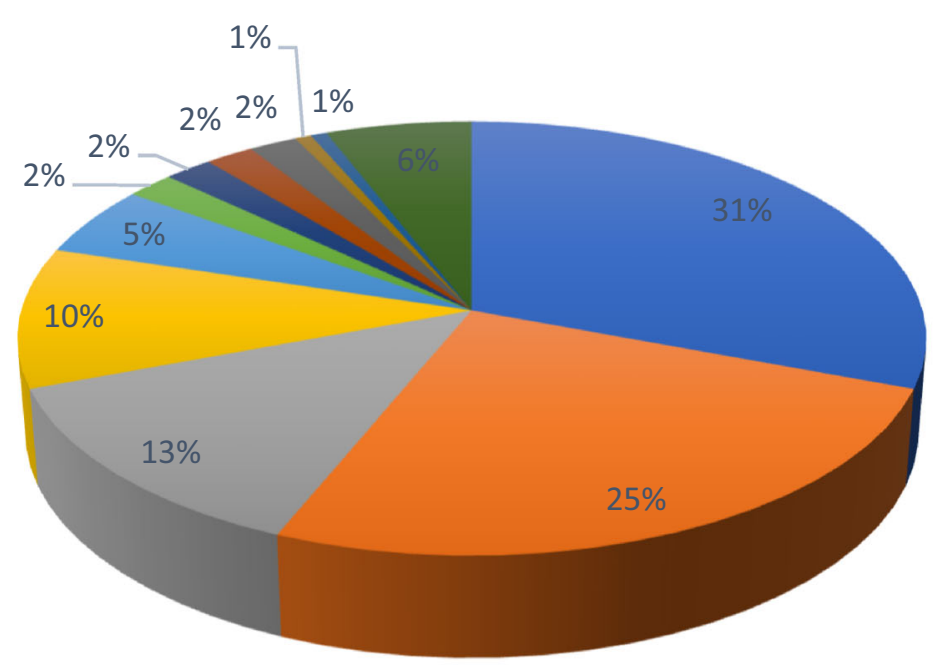

Acinetobacter baumannii

Klebsiella pneumoniae

Escherichia coli

Flavobacterium

Pseudomonas aeruginosa

Proteus mirabilis

Enterobacter cloacae

Enterobacter aerogenes

Klebsiella odorata

Enterobacter asburiae

Enterobacter agglomerans

Other

Fig. 2 Species found in carbapenem-resistant gram-negative bacterial infections during 2013-2020

Table 4 Antimicrobial resistance of 153 carbapenem-resistant gram-negative bacterial infection recipients

\begin{tabular}{llllll}
\hline Antimicrobial & $\begin{array}{l}\text { A. baumannii } \\
(\boldsymbol{n}=\mathbf{4 7})\end{array}$ & $\begin{array}{l}\text { K. pneumoniae } \\
(\mathbf{n}=\mathbf{3 9})\end{array}$ & $\begin{array}{l}\boldsymbol{E} \text {. coli } \\
(\boldsymbol{n}=\mathbf{2 0})\end{array}$ & $\begin{array}{l}\text { Other } \\
(\boldsymbol{n}=\mathbf{4 7})\end{array}$ & $\begin{array}{l}\text { Total strains } \\
(\boldsymbol{n}=\mathbf{1 5 3})\end{array}$ \\
\hline Amikacin & $43(91.5)$ & $21(53.8)$ & $5(25)$ & $31(65)$ & 65.4 \\
Aztreonam & $46(97.9)$ & $36(92.3)$ & $20(100)$ & $46(97.9)$ & 96.7 \\
Ciprofloxacin & $45(95.7)$ & $32(82.1)$ & $12(60)$ & $35(74.5)$ & 81.0 \\
Gentamicin & $44(93.6)$ & $31(79.5)$ & $10(50)$ & $35(74.5)$ & 78.4 \\
Levofloxacin & $42(89.4)$ & $30(76.9)$ & $12(60)$ & $34(72.3)$ & 77.1 \\
Sulfamethoxazole & $38(80.9)$ & $24(61.5)$ & $12(60)$ & $31(66)$ & 68.6 \\
Tobramycin & $44(93.6)$ & $29(74.4)$ & $10(50)$ & $40(85.1)$ & 80.4 \\
Piperacillin- & $45(95.7)$ & $32(82.1)$ & $13(65)$ & $40(85.1)$ & 85.0 \\
\multicolumn{1}{c}{ tazobactam } & & $38(97.4)$ & & & 83.0 \\
Macrodantin & $45(95.7)$ & $13(33.3)$ & $2(10)$ & $22(46.8)$ & 33.3 \\
Tigecycline & $14(29.8)$ & & & & $38(80.9)$ \\
\hline
\end{tabular}

Values are no. (\%) of resistant strains, except as indicated

surprising because requiring mechanical ventilation and septic shock are indicators of the severity of illness. This finding underscores the importance of early therapy, including timely and adequate antibiotic therapy, which may increase the survival rate of ASOT recipients suffering from septic shock or respiratory failure [18]. In line with our previous study, platelet 


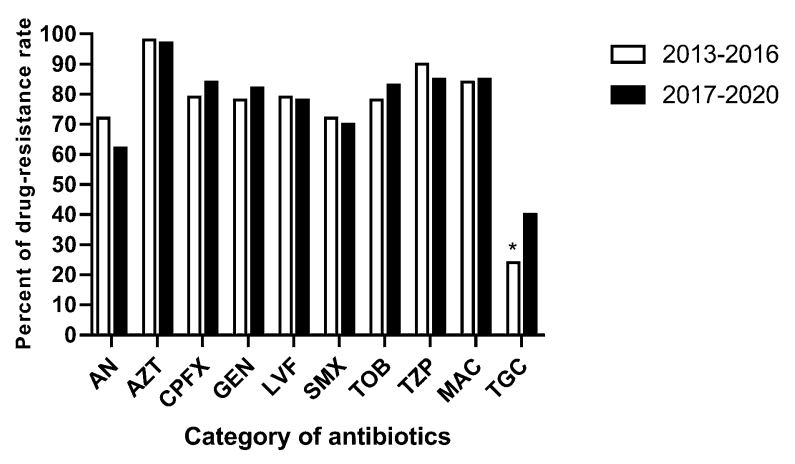

Fig. 3 Comparisons between two halves of the period (2013-2016 versus 2017-2020) in ten drug resistance rates to carbapenem-resistant gram-negative bacterial isolates. The drug resistance rate of tigecycline was significantly increased from 24 to $40 \%$ as time went on $(P=0.04) .{ }^{*} P$ value is statistically significant. $A N$ amikacin, $A Z T$ aztreonam, CPFX ciprofloxacin, $G E N$ gentamicin, $L V F$ levofloxacin, $S M X$ sulfamethoxazole, $T O B$ tobramycin, TZP piperacillin-tazobactam, $M A C$ macrodantin, $T G C$ tigecycline

count $<50,000 / \mathrm{mm}^{3}$ predicted adverse clinical outcomes of CR-GNB-infected recipients [19]. It probably resulted from the key role of the platelets in the development of disseminated intravascular coagulation and multiple organ failure despite the unclear mechanisms [20].

Donor-derived infections, especially CR-GNB infections, were increasingly reported with adverse impacts on the recipient outcomes in the past decades [21-23]. In line with previous study, we found that donor-derived infections were not related to mortality with a $P$ value of 0.997, indicating CR-GNB-infected or -colonized donors could also be transplanted with prophylactic antibiotic therapy in the current era of donor shortages [23].

Choosing appropriate antibiotics for CRGNB infections is a great challenge due to the complex clinical situation. The overall drug resistance rates of pathogens to various categories of antibiotics, antibiotic concentration, tissue penetration at the site of infections, and renal and liver function for ASOT recipients must be considered.
TGC is a broad-spectrum antibiotic with in vitro activity against CR-GNB and approved as an appropriate therapy except for CRPA. Approximately $33.3 \%$ of CR-GNB pathogens in the present study were resistant to TGC, in line with the previous study reporting the drug resistance rate of $37.8 \%$ among inpatients [24]. After eliminating the impact of CRPA $(n=9)$ on the total drug resistance rate, there were only $27.5 \%$ other CR-GNBs resistant to TGC, making it an appropriate 'old' antibiotic for the treatment of CR-GNB infections among ASOT recipients. In line with previous studies, combination therapy, based on TGC, was recommended as the most effective regimen used for CR-GNB infections, particularly for CRE infections in China [25]. TGC performs poorly in bacteremia because of the poor plasma concentration [26]. We did not monitor plasma or tissue concentrations of TGC because of the retrospective nature. Guner et al. revealed that TGC, used alone or in combination with other antibiotics, was effective in CRAB infections [27]. However, there was a significantly increasing trend in the drug resistance rate of TGC (from 24 to $40 \%, P=0.04$ ) as time went on, which may be an alert for cautious prescription of TGC.

We also revealed that drug resistance rates of all CR-GNB isolates to nine of ten antibiotics involved were $>60 \%$ except for TGC. CRAB $(n=47)$ and CRKP $(n=39)$ were the most common pathogens in this cohort. Consistent with the previous studies, CRKP and CRAB were both highly resistant (> 50\%) to the other nine of ten antibiotics except for TGC [28, 29]. For carbapenem-resistant E. coli and other CR-GNB organisms, drug resistance rates were basically lower than for CRKP and CRAB. These other nine antibiotics were not recommended as empirical therapy for CR-GNB infections because of the high probability of failure based on our findings. Several previous studies proved that some of these antibiotics, such as trimethoprim-sulfamethoxazole and amikacin, performed well in CRKP infections among ASOT recipients, so we suggest that these choices may be prescribed after identification of susceptibility $[30,31]$. The new rapid diagnostic options for CR-GNB, such as next-generation 
sequencing and ATP bioluminescence, are recommended in treatment to improve outcomes, but are limited because of the exorbitant costs [32].

Polymyxins, both colistin and polymyxin B, were successful and safe choices for ASOT recipients reported in previous studies but not analyzed in this cohort because of the lack of susceptibility profiles in most patients [33, 34]. Cefiderocol, a novel cephalosporin designed to treat all CR-GNB infections, is still in the clinical trial stage with promising prospects [35]. Ceftazidime avibactam has been reported to have better effects than TGC, thus being approved to treat CR-GNB infections in China since May 21, 2019 [36, 37]. However, administering combination or 'new' antibiotic therapy to all severe CR-GNB infected patients, including some individuals with XDR or pan-drug-resistant pathogens, is not a sustainable decision due to the concerns about deteriorating resistances. In the present era of emerging drug resistance, prospective steps may be suggested to facilitate pharmacologic and molecular studies to speed up the process of creating clinical breakpoints for novel antibiotics, including all new antibiotics mentioned above, and define the mechanism of drug resistance.

Certain limitations need to be clarified in our study. First, due to the retrospective nature of a monocentric study, our research is limited by deficient data retrieved from the electronic medical records. The impact of antibiotics, comparing 'new' with 'old,' may hardly be evaluated in our cohort and needs to be investigated in a prospective study. Second, our study could be divided into various groups, such as different age groups, to provide more detailed information, which may be done in the future. Third, the immune status of ASOT recipients may play an important role, as all patients were immunosuppressed; therefore, we will reveal the relationship related to the rate of CD4/CD8 or IgG/IgA/IgM levels and clinical outcomes in the future. Finally, with the development of medical technology, it might be possible to use novel molecular technology or test methods to investigate the mechanism and allow prompt rapid diagnoses of infections.

\section{CONCLUSIONS}

CR-GNB is widespread as a global medical crisis associated with high morbidity and mortality rates among ASOT recipients. This study reveals that mechanical ventilation, septic shock, and low platelet count represent three independent risk factors related to the mortality of ASOT recipients with CR-GNB infections. With a significantly increasing trend of the drug resistance rate, we suggest that TGC may be used under rigorous administration for the treatment of CR-GNB-infected recipients.

\section{ACKNOWLEDGEMENTS}

We thank Profs. Tubao Yang and Junxia Yan for their help in verifying the statistical analysis in this manuscript.

Funding. This work and the journal's rapid service fee were supported by Fundamental Research Funds for the Central Universities of Central South University, China, and Natural Science Foundation of Hunan Province, China (2019JJ40524).

Authorship. All named authors meet the International Committee of Medical Journal Editors criteria for authorship for this article, take responsibility for the integrity of the work as a whole, and have given their approval for this version to be published.

Authorship Contributions. QW and JP conceived and designed the study; DW, CC, TL and YJ collected and cleaned the data; DW analyzed the data, interpreted the results and wrote the first draft of the manuscript; CC, TL and YJ interpreted the results; all authors critically revised the manuscript and gave final approval for publication.

Disclosures. Di $\mathrm{Wu}$, Chunmei Chen, Taohua Liu, Yan Jia, Qiquan Wan and Jie Peng have nothing to disclose. 
Compliance with Ethics Guidelines. The Institutional Review Board of the Third-Xiangya Hospital of Central South University endorsed this study protocol prior to data collection (number: 2020-S629). The Institutional Review Board approved the waiver of patient informed consent because this was a retrospective cohort study whose information was obtained from electrical medical records and this study did not directly interfere with the enrolled patients; in addition, the data were de-identified and anonymously analyzed. Our study was conducted according to the Declaration of Helsinki and the Declaration of Istanbul, and no donors influenced or paid for our study. Privacy statement: the authors guarantee patient data confidentiality.

Data Availability. The datasets generated during and/or analyzed during the current study are available from the corresponding author on reasonable request.

Open Access. This article is licensed under a Creative Commons Attribution-NonCommercial 4.0 International License, which permits any non-commercial use, sharing, adaptation, distribution and reproduction in any medium or format, as long as you give appropriate credit to the original author(s) and the source, provide a link to the Creative Commons licence, and indicate if changes were made. The images or other third party material in this article are included in the article's Creative Commons licence, unless indicated otherwise in a credit line to the material. If material is not included in the article's Creative Commons licence and your intended use is not permitted by statutory regulation or exceeds the permitted use, you will need to obtain permission directly from the copyright holder. To view a copy of this licence, visit http://creativecommons.org/licenses/by$\mathrm{nc} / 4.0 /$.

\section{REFERENCES}

1. Xu L, Sun X, Ma X. Systematic review and metaanalysis of mortality of patients infected with carbapenem-resistant Klebsiella pneumoniae. Ann Clin Microbiol Antimicrob. 2017;16:18-18.

2. Kohira N, West J, Ito A, Ito-Horiyama T, Nakamura R, Sato T, Rittenhouse S, Tsuji M, Yamano Y. In vitro antimicrobial activity of a siderophore cephalosporin, S-649266, against enterobacteriaceae clinical isolates, including carbapenem-resistant strains. Antimicrob Agents Chemother. 2016;60:729-34.

3. Freire MP, Oshiro ICVS, Pierrotti LC, Bonazzi PR, de Oliveira LM, Song ATW, Camargo $\mathrm{CH}$, van der Heijden IM, Rossi F, Costa SF, D'Albuquerque LAC, Abdala E. Carbapenem-resistant enterobacteriaceae acquired before liver transplantation. Transplantation. 2017;101:811-20.

4. Pereira MR, Scully BF, Pouch SM, Uhlemann A, Goudie S, Emond JE, Verna EC. Risk factors and outcomes of carbapenem-resistant Klebsiella pneumoniae infections in liver transplant recipients. Liver Transplant. 2015;21:1511-9.

5. Shields RK, Clancy CJ, Gillis LM, Kwak EJ, Silveira FP, Massih RC, Eschenauer GA, Potoski BA, Nguyen $\mathrm{MH}$. Epidemiology, clinical characteristics and outcomes of extensively drug-resistant Acinetobacter baumannii infections among solid organ transplant recipients. PLoS ONE. 2012;7:e52349.

6. Wan QQ, Ye QF, Yuan H. Multidrug-resistant Gramnegative bacteria in solid organ transplant recipients with bacteremias. Eur J Clin Microbiol Infect Dis. $2015 ; 34: 431-7$.

7. Qiao B, Wu J, Wan Q, Zhang S, Ye Q. Factors influencing mortality in abdominal solid organ transplant recipients with multidrug-resistant gram-negative bacteremia. BMC Infect Dis. $2017 ; 17: 171$

8. Horan TC, Andrus M, Dudeck MA. CDC/NHSN surveillance definition of health care-associated infection and criteria for specific types of infections in the acute care setting. Am J Infect Control. 2008;36:309-32.

9. Wolfe CR, Ison MG. Donor-derived infections: Guidelines from the American Society of Transplantation Infectious Diseases Community of Practice. Clin Transplant. 2019;33:e13547.

10. Shankar-Hari M, Phillips GS, Levy ML, Seymour CW, Liu VX, Deutschman CS, Angus DC, Rubenfeld GD, Singer M. Developing a new definition and assessing new clinical criteria for septic shock. JAMA. 2016;315:775.

11. Wu D, Chen C, Liu T, Wan Q. Risk factors for acquisition of carbapenem-resistant Klebsiella pneumoniae and mortality among abdominal solid organ 
transplant recipients with $K$. pneumoniae infections. Med Sci Monit. 2020;26:e922996.

12. Varotti G, Dodi F, Terulla A, Santori G, Mariottini G, Bertocchi M, Marchese A, Fontana I. Impact of carbapenem-resistant Klebsiella pneumoniae (CR-KP) infections in kidney transplantation. Transpl Infect Dis. 2017;19:e12757.

13. Mouloudi E, Massa E, Papadopoulos S, Iosifidis E, Roilides I, Theodoridou T, Piperidou M, Orphanou A, Passakiotou M, Imvrios G, Fouzas I, Papanikolaou V, Gritsi-Gerogianni N. Bloodstream infections caused by carbapenemase-producing Klebsiella pneumoniae among intensive care unit patients after orthotopic liver transplantation: risk factors for infection and impact of resistance on outcomes. Transpl Proc. 2014;46:3216-8.

14. Aguado JM, Silva JT, Fernández-Ruiz M, Cordero E, Fortún J, Gudiol C, Martínez-Martínez L, Vidal E, Almenar L, Almirante B, Cantón R, Carratalá J, Caston JJ, Cercenado E, Cervera C, Cisneros JM, Crespo-Leiro MG, Cuervas-Mons V, Elizalde-Fernández J, Fariñas $\mathrm{MC}$, Gavaldà J, Goyanes $\mathrm{MJ}$, Gutiérrez-Gutiérrez B, Hernández D, Len O, LópezAndujar R, López-Medrano F, Martín-Dávila P, Montejo M, Moreno A, Oliver A, Pascual A, PérezNadales E, Román-Broto A, San-Juan R, Serón D, Solé-Jover A, Valerio M, Muñoz P, Torre-Cisneros J. Management of multidrug resistant Gram-negative bacilli infections in solid organ transplant recipients: SET/GESITRA-SEIMC/REIPI recommendations. Transpl Rev. 2018;32:36-57.

15. Oriol I, Sabé N, Melilli E, Lladó L, González-Costello J, Soldevila L, Carratalà J. Factors influencing mortality in solid organ transplant recipients with bloodstream infection. Clin Microbiol Infect. 2015;21:1104.e9-1104.e14.

16. Mazza E, Prosperi M, Panzeri MF, Limuti R, Nichelatti M, De Gasperi A. Carbapenem-resistant Klebsiella pneumoniae infections early after liver transplantation: a single-center experience. Transpl Proc. 2017;49:677-81.

17. Bodro M, Sabé N, Tubau F, Lladó L, Baliellas C, Roca J, Cruzado JM, Carratalà J. Risk factors and outcomes of bacteremia caused by drug-resistant ESKAPE pathogens in solid-organ transplant recipients. Transpl J. 2013;96:843-9.

18. Garnacho-Montero J, Gutierrez-Pizarraya A, Escoresca-Ortega A, Fernandez-Delgado E, Lopez-Sanchez JM. Adequate antibiotic therapy prior to ICU admission in patients with severe sepsis and septic shock reduces hospital mortality. Crit Care. 2015;19:302.
19. Wan Q, Ye Q, Zhou J. Mortality predictors of bloodstream infections in solid-organ transplant recipients. Exp Clin Transpl. 2013;11:211-4.

20. Russwurm S, Vickers J, Meier-Hellmann A, Spangenberg P, Bredle D, Reinhart K, Losche W. Platelet and leukocyte activation correlate with the severity of septic organ dysfunction. Shock. 2002;17:263-8.

21. Nellore A, Fishman JA. Donor-derived infections and infectious risk in xenotransplantation and allotransplantation. Xenotransplantation. 2018;25: e12423.

22. Tong L, Hu X, Huang F, Huang S, Li L, Tang Z, Yao J, Xu J, Zhu Y, Chen Y, He X, Guan X, Cai C. Clinical impacts and outcomes with possible donor-derived infection in infected donor liver transplantation: a single-center retrospective study in China. J Infect Dis. 2020;221:S164-73.

23. Errico G, Gagliotti C, Monaco M, Masiero L, Gaibani P, Ambretti S, Landini MP, Arezzo SD, Di Caro A, Parisi SG, Palù G, Vespasiano F, Morsillo F, Moro ML, Procaccio F, Ricci A, Grossi PA, Pantosti A, Nanni Costa A, Farina C, Vailati F, Gesu G, Vismara C, Arghittu M, Colombo R, Torresani E, Rossi L, Conaldi PG, Gona F, Cambieri P, Marone P, Venditti C, Fernandez AG, Mancini C, Cusi M, De Angelis LH, Fossati L, Finarelli AC, De Cillia C, Sangiorgi G, Pinna AD, Stella F, Viale P, Colledan M, Platto M, Bonizzoli M, Peris A, Torelli R, Vesconi S, Cibelli E, De Carlis L, De Gasperi A, Ravini M, Carrinola R, Coluccio E, Dondossola D, Rossi G, Santambrogio L, Tosi D, Feltrin G, Rago C, Cillo U, Da Riva A, Rea F, Sparacino V, Bertani A, Canzonieri M, Gridelli B, Mularoni A, Spada M, Carrara E, Armini AMD, Paladini P, Adorno D, Valeri M, Caprio M, Di Ciaccio P, Puoti F, Berloco P, Auria BD, Maldarelli F, Paglialunga G, Pugliese F, Rossi M, Venuta F, Amoroso A, Giacometti R, Rinaldi M, Salizzoni M. Colonization and infection due to carbapenemase-producing Enterobacteriaceae in liver and lung transplant recipients and donorderived transmission: a prospective cohort study conducted in Italy. Clin Microbiol Infect. 2019;25: 203-9.

24. Park Y, Choi Q, Kwon GC, Koo SH. Molecular epidemiology and mechanisms of tigecycline resistance in carbapenem-resistant Klebsiella pneumoniae isolates. J Clin Lab Anal. 2020;34:e23506.

25. Guan X, He L, Hu B, Hu J, Huang X, Lai G, Li Y, Liu Y, Ni Y, Qiu H, Shao Z, Shi Y, Wang M, Wang R, Wu D, Xie C, Xu Y, Yang F, Yu K, Yu Y, Zhang J, Zhuo C. Laboratory diagnosis, clinical management and infection control of the infections caused by extensively drug-resistant Gram-negative bacilli: a Chinese consensus statement. Clin Microbiol Infect. 2016;22:S15-25. 
26. McGovern PC, Wible M, El-Tahtawy A, Biswas P, Meyer RD. All-cause mortality imbalance in the tigecycline phase 3 and 4 clinical trials. Int J Antimicrob Agents. 2013;41:463-7.

27. Guner R, Hasanoglu I, Keske S, Kalem AK, Tasyaran MA. Outcomes in patients infected with carbapenem-resistant Acinetobacter baumannii and treated with tigecycline alone or in combination therapy. Infection. 2011;39:515-8.

28. El-Badawy MF, Abdelwahab SF, Alghamdi SA, Shohayeb MM. Characterization of phenotypic and genotypic traits of carbapenem-resistant Acinetobacter baumannii clinical isolates recovered from a tertiary care hospital in Taif, Saudi Arabia. Infect Drug Resist. 2019;12:3113-24.

29. Zeng L, Deng Q, Zeng T, Liu Y, Zhang J, Cao X. Prevalence of carbapenem-resistant Klebsiella pneumoniae infection in Southern China: clinical characteristics, antimicrobial resistance, virulence, and geographic distribution. Microbiol Drug Resist. 2020;26:483-91.

30. Murri R, Fiori B, Spanu T, Mastrorosa I, Giovannenze F, Taccari F, Palazzolo C, Scoppettuolo G, Ventura G, Sanguinetti M, Cauda R, Fantoni M. Trimethoprim-sulfamethoxazole therapy for patients with carbapenemase-producing Klebsiella pneumoniae infections: retrospective single-center case series. Infection. 2017;45:209-13.

31. Freire MP, Abdala E, Moura ML, de Paula FJ, Spadao F, Caiaffa-Filho HH, David-Neto E, Nahas WC, Pierrotti LC. Risk factors and outcome of infections with Klebsiella pneumoniae carbapenemase-producing $K$. pneumoniae in kidney transplant recipients. Infection. 2015;43:315-23.

32. Cai Y, Seah CL, Leck H, Lim T, Teo JQ, Lee W, Tan T, Koh T, Ee PLR, Kwa AL. Rapid antibiotic combination testing for carbapenem-resistant Gram- negative bacteria within six hours using ATP bioluminescence. Antimicrob Agents Chemother. 2018;62:1.

33. Heldman MR, Guo K, Nelson B, Babu T, Ison MG. Treatment of multidrug-resistant gram-negative bacilli after solid organ transplant: outcomes and complications. Transpl Infect Dis. 2020:e13474.

34. Dan JM, Mendler MH, Hemming AW, Aslam S. High-dose tigecycline and colistin for successful treatment of disseminated carbapenem-resistant Klebsiella pneumoniae infection in a liver transplant recipient. Case Rep. 2014:bcr2014205865.

35. Aoki T, Yoshizawa H, Yamawaki K, Yokoo K, Sato J, Hisakawa S, Hasegawa Y, Kusano H, Sano M, Sugimoto H, Nishitani Y, Sato T, Tsuji M, Nakamura R, Nishikawa T, Yamano Y. Cefiderocol (S-649266), a new siderophore cephalosporin exhibiting potent activities against Pseudomonas aeruginosa and other gram-negative pathogens including multi-drug resistant bacteria: structure activity relationship. Eur J Med Chem. 2018;155:847-68.

36. van Duin D, Lok JJ, Earley M, Cober E, Richter SS, Perez F, Salata RA, Kalayjian RC, Watkins RR, Doi Y, Kaye KS, Fowler VJ, Paterson DL, Bonomo RA, Evans $S$. Colistin versus ceftazidime-avibactam in the treatment of infections due to carbapenem-resistant enterobacteriaceae. Clin Infect Dis. 2018;66: 163-71.

37. Lewinsohn DM, Leonard MK, LoBue PA, Cohn DL, Daley CL, Desmond E, Keane J, Lewinsohn DA, Loeffler AM, Mazurek GH, Brien RJO, Pai M, Richeldi L, Salfinger M, Shinnick TM, Sterling TR, Warshauer DM, Woods GL. Official American Thoracic Society/Infectious Diseases Society of America/Centers for Disease Control and Prevention clinical practice guidelines: diagnosis of tuberculosis in adults and children. Clin Infect Dis. 2017;64:111-5. 